\title{
INNOVATIVE APPROACH TO WHEAT-FLAX FLOUR PRODUCING
}

\author{
Irina .S. Vitol ${ }^{1 *}$, Elena P. Meleshkina ${ }^{1}$, Ivan A. Kechkin $^{1}$ and Georgy N. Pankratov ${ }^{1}$ \\ ${ }^{1}$ All-Russian Scientific Research Institute of Grain and Products of its Processing - a branch of the V.M. Gorbatov Federal Research \\ Center for Food Systems of Russian Academy of Sciences, Moscow, Russian Federation
}

\begin{abstract}
An innovative approach to the obtaining of wheat-flax flour has been developed, it is based on the use of polished wheat groats and semolina for subsequent grinding together with flax seeds. The technological scheme for grinding a two-component grain mixture included one break system and three reduction systems. It is found that the introduction of flax seeds into the milling grist has a significant effect on all quality indicators, and the greatest effect was revealed at the processing of a mixture of semolina and flax seeds. Statistical analysis made it possible to establish a linear character of the dependence of the flour whiteness on the yield $(\mathrm{R}=0.96$ 0.99). The protein and fat content in wheat-flax flour № 1 (wheat groats + flax) is $14.0 \%$ and $3.8 \%$, and in wheat-flax flour № 2 (semolina + flax) $-12.5 \%$ and $3.6 \%$, respectively. The essential linolenic acid content in wheat-flax flour №1 and №2 is 49.34\% and 45.55\%, respectively, while it is $2.95 \%$ for top-grade wheat flour. The new approach made it possible to significantly simplify the grinding process, abandon multi-grade grinding, and achieve a uniform distribution of fat among flour varieties. The resulting wheat-flax flour contains the required amount of PUFAs in accordance with the recommended consumption rates and the inclusion of products from it in the diet of a modern person can compensate for the lack of PUFAs of the $₫-3$ family.
\end{abstract}

\section{Introduction}

For Russia, as well as for most countries, the problem of a balanced, healthy diet is very relevant against the background of underconsumption of substances necessary for the body, namely, dietary fiber, proteins, polyunsaturated fatty acids (PUFAs), vitamins, minerals, which negatively affects human health. One of the most effective ways of solving this problem is to produce specialized enriched food products. Recently, the so-called composite grain mixtures, the component composition of which is balanced in macronutrients, enriched with micronutrients, and contains valuable minor components that ensure their functional properties, have been widely studied and introduced into the practice of food production on a grain basis [1-5].

It is known that wheat flour, especially top-grade flour, contains insufficient quantity of valuable nutrients, in particular, of PUFAs of the $₫-3$ and $₫-6$ families. The introduction of flax seeds into the mixture can significantly enrich and balance the composition of the resulting grain products. The unique composition of the protein and lipid complexes of flax seeds, which have a high content of PUFAs, essential amino acids, predominant portion of albumin-globulin fraction of soluble proteins, indicates the high nutritional and biological value of flax seeds [6,7].

The introduction of whole flax seeds into the grain mixture and their coprocessing along with wheat grain allows to use the entire biopotential of flax and significantly (3-4 times) reduce its amount in the grain mixture compared to the use of the so-called flax flour from linseed cake, which has a positive effect on baking, organoleptical and consumer properties of finished flour products $[6,8,9]$.

The purpose of the study is to develop an innovative approach to wheat-flax flour producing and to assess quality of wheat-flax flour, obtained by joint grinding of a wheat-flax mixture

\section{Object and research methods}

The object of the study was wheat grain processing products (wheat groats, type "Poltavskaya", semolina) and white oil flax seeds, as well as wheat-flax flour obtained from a binary mixture (93\% groats and $7 \%$ flax seeds).

The total protein content was determined by the Kjeldahl method $(\mathrm{N} \times 6.25)$ (GOST 10846-91); fat according to Soxhlet (GOST 29033-91) [10]. Flour

\footnotetext{
* Correspoding author: vitolis@yandex.ru
} 
whiteness was determined by measuring the reflectivity of the compacted-smoothed flour surface using a photoelectric device (GOST 26361-2013), ash content by burning flour, followed by determining the mass of the incombustible residue (GOST 27494-2016). Fatty acid composition - by gas chromatography (gas chromatograph $6890 \mathrm{~N}$ with a mass-selective detector Agilent 5975C, USA).

\section{Results and discussion}

Research carried out at the All-Russian Research Institute of grain and its processing products has shown the fundamental possibility of joint processing of cereals and oilseeds, which are characterized by significant differences in physical and chemical properties $[6,8]$.
It was found that the fat content in the wheat-flax flour is proportional to the amount of flax seeds in the binary mixture (Fig. 1).

The developed technological scheme of multi-grade milling of a binary grain mixture, consisting of $93 \%$ wheat grain and $7 \%$ flax seeds, made it possible to obtain three varieties of wheat-flax flour with increased nutritional value. The content of flax seeds in the mixture was determined based on the recommended levels of consumption of food and bioactive substances [11] and averaged $7 \%$.

At the same time, uneven distribution of fat among flour varieties was revealed.

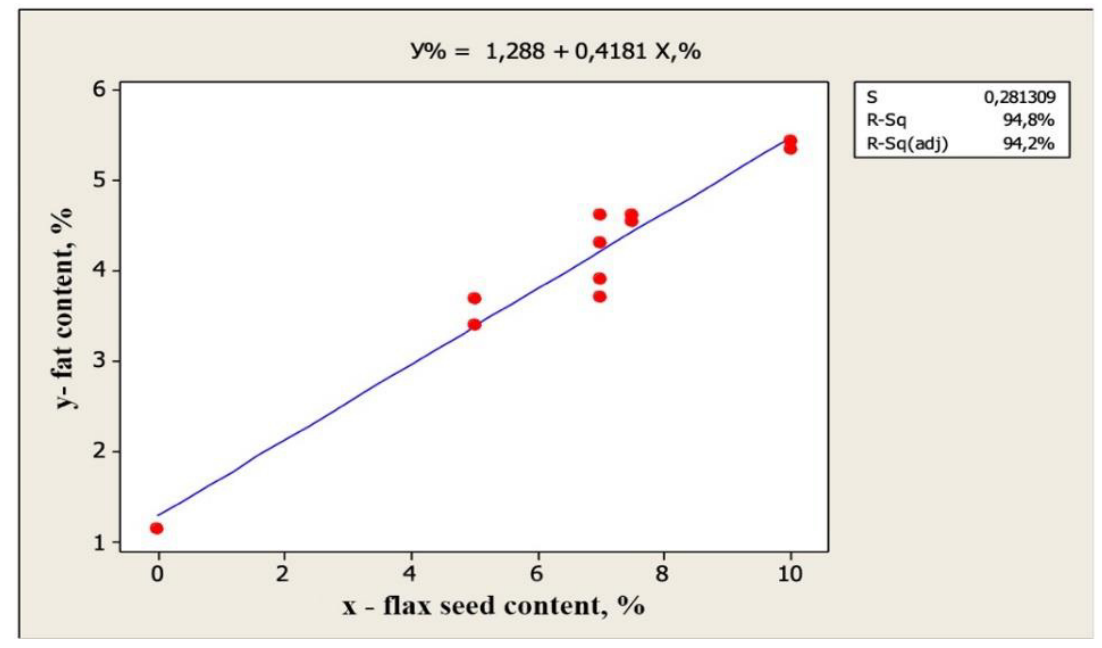

Fig 1. Dependence of the fat content of flour on the flax seeds amount in the binary grain mixture

In this regard, a new approach to the obtaining of wheat-flaxseed flour was proposed, which is a singlegrade grinding of a binary grain mixture, in which, instead of wheat grain, polished wheat groats, such as "Poltavskaya" and semolina are used, which made it possible to significantly simplify the grinding process and level the uneven distribution fat by types of flour.

The technological scheme for milling a twocomponent grain mixture included one break system (b.s.) and three reduction systems (r.s.). Break process was carried out using a roller mill RSA with an interroller gap of $0.05 \mathrm{~mm}$, which ensures flour extraction of at least $50 \%$. Reduction was carried out on the grinding part of the MLU 202 unit with a minimum inter-roll gap of $0.01 \mathrm{~mm}$. (fig. 2)

The greatest influence on all quality indicators was revealed at the processing a mixture of semolina and flax seeds. The resulting wheat-flaxseed flour contains the required amount of PUFAs in accordance with the recommended consumption rates [11], and the inclusion of products from it in the diet of a modern person can compensate for the lack of PUFAs of the $₫-3$ family.

To assess the effect of flax seeds on the technological qualities of flour, comparative grinding was carried out (P1 - P4) (Table 1):
1. Top-grade wheat flour (control 1, P1);

2. Wheat-flax flour № 1 (93\% of wheat groats $+7 \%$ flax seeds, P2);

3. Semolina flour (control 2, PZ);

4. Wheat-flax flour № 2 (93\% of semolina $+7 \%$ flax seeds, P4).

When comparing the change in the whiteness of flour depending on the type of raw material and the presence of flax seeds with a flour yield of $80 \%$, the following was found: the whiteness of flour (BM) from wheat groats - 29.2 units, and with the addition of flax seeds - 8.0 units., from semolina - 58.7 units, from its mixture with flax seeds -46.6 units. This confirms the previously obtained data on the significant effect of the presence of the flax seeds in the mixture on the whiteness of high-grade flour [6]. Statistical analysis made it possible to establish a linear character of the dependence of the flour whiteness on the yield $(R=0.96$ - 0.99). The ash content of flour from a mixture of wheat and flax increased by $0.03 \%$, the one of flour from a mixture of semolina and flax increased by $0.1 \%$ compared to the control.

The total protein content increased on average by 2.0-2.5\% and amounted to $14.0 \%$ for wheat-flax flour (wheat groats + flax; P2), and $12.5 \%$ for wheat-flax flour № 2 (semolina + flax; P4). 
I b.s.

$0,05 \mathrm{~mm}$

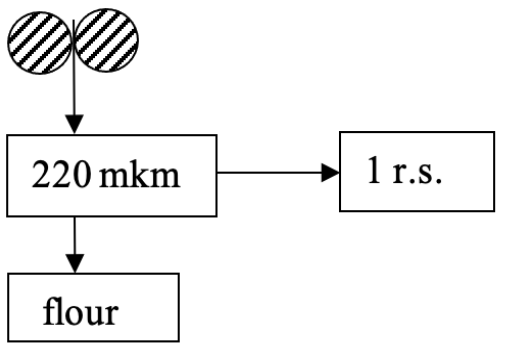

1 r.s

$0,01 \mathrm{~mm}$

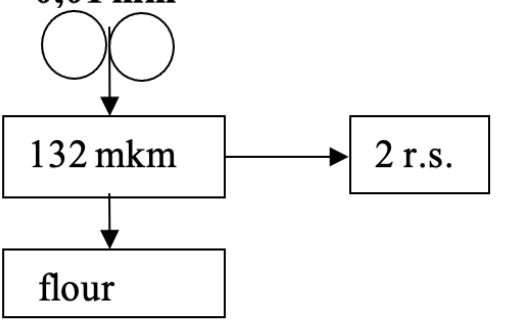

2 r.s.

$0,01 \mathrm{~mm}$

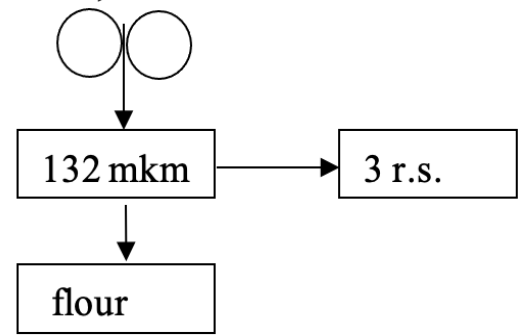

3 r.s.

$0,01 \mathrm{~mm}$

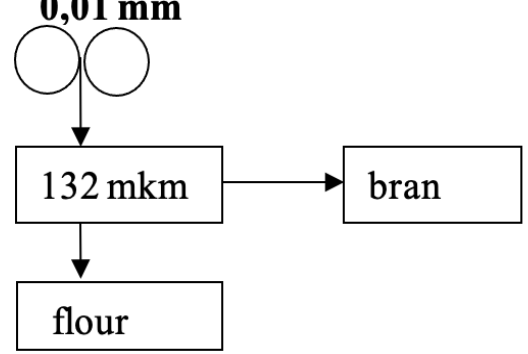

Fig. 2. Scheme of a binary mixtures grinding

Table 1. Technological quality indicators of flour

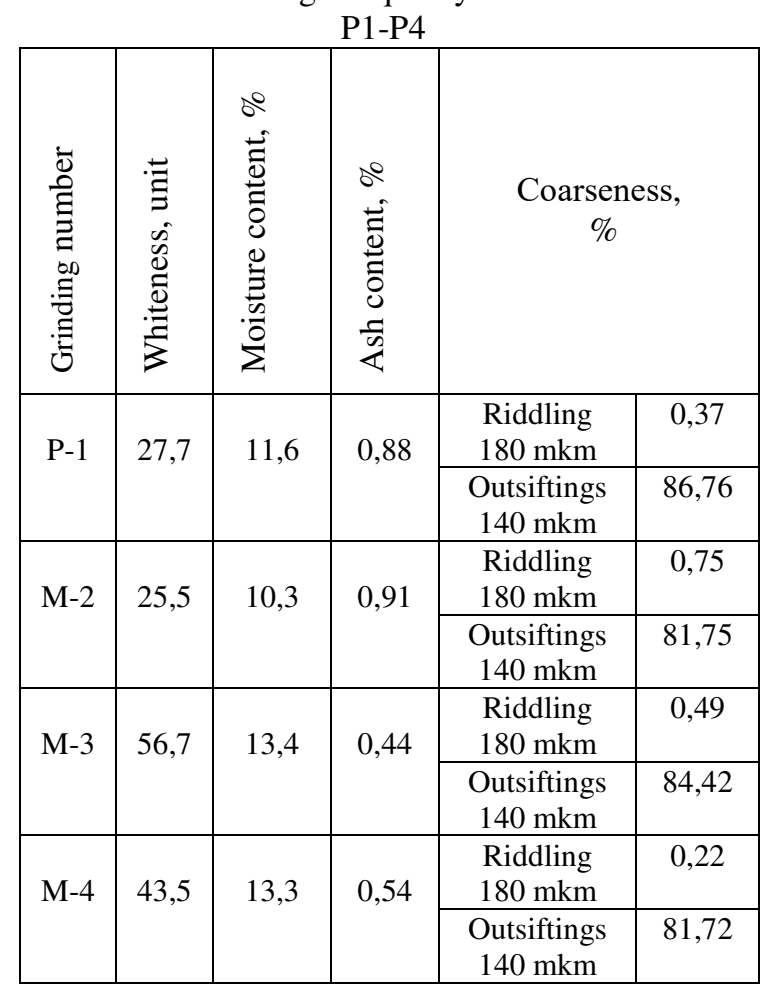

Based on the fat content of wheat groats equal to $1.4 \%$, the one of semolina equal to $1.2 \%$ and the fact that the introduction of $7 \%$ of flax seeds into the grain mixture increases the fat content by an average of $2.8 \%$, the fat content of wheat-flax flour №1 (wheat groats + flax; P2) amounted to $3.8 \%$, of wheat-flax flour №2 (semolina + flax; P4) $-3.6 \%$. The essential linolenic acid content of wheat-flax flour №1 and №2 amounted to $49.34 \%$ and $45.55 \%$, respectively, while it is $2.95 \%$ for top-grade wheat flour.

\section{Conclusion}

The new approach to the producing of wheat-flax flour using polished wheat groats and semolina for its subsequent grinding together with flax seeds has been proposed and given scientific credence, which made it possible to significantly simplify the grinding process, abandon multi-grade grinding, and achieve a uniform distribution of fat among flour varieties.

The greatest effect on all quality indicators was revealed at the processing of a mixture of semolina and flax seeds. The resulting wheat-flax flour contains the required amount of PUFAs in accordance with the recommended consumption rates [11] and the inclusion of products from it in the diet of a modern person can compensate for the lack of PUFAs of the $\omega$ 3 family. 


\section{References}

1. T.B. Tsyganova, I.E. Minevel, V.A. Zubov, L.L. Osipova, Food value of flax seeds and promising directions of their processing, Kaluga: Eidos, 124 p., Russian (2010)

2. K.B. Gutte, A.K. Sahoo, R.C. Ranveer, Bioactive Components of Flaxseed and Its Health Benefits, International Journal of Pharmaceutical Sciences Review and Research. 31(1). P. $42-51$ (2015)

3. K.N. Niziyevskaya, G.P. Chekryga, O.K. Motovilov Study of technical indicators of flax seeds of white and brown for use in the food industry, Polzunovsky Bulletin. 1. P. 49-53 (2018)

4. M.A. Sigareva, M.P. Mogyl, T.Sh. Shaltumayev, The use of flax seed processing products for the production of high food value products, News of higher educational institutions. Food technology. 5-6. P. 42-45 (2015)

5. H.N. Rabetafika, V. Van Remoortel, S. Danthine, M. Paquot. C. Blecker, Flaxseed Proteins: Food Use and Health Benefits, International Journal of Food Science and Technology. 46. P. 221-228 (2011) doi:10.111/j.1365-2621.2010.02477.x.

6. G.N. Pankratov, E.P. Melehkina, I.S. Vitol, I.A. Kechkin, Yu.R. Nagainikova, S.N. Kolomiets Wheat-linen flour: conditions for obtaining and biochemical features, Russian agricultural science. 3. P. 65-70 (2020) doi: 10.31857 / S250026272000163.

7. Goyal, V. Sharma, N. Upadhyay, S. Gill, M. Sihag, Flax and Flaxseed Oil: An Ancient Medicine \& Modern Functional Food, Journal Food Science Technology. 51(9) P.1633-1653 (2014) doi: 10.1007/s13197-013-1247-9.

8. G.N. Pankratov, I.S. Vitol, E.P. Meleshkina, Yu.R. Nagainikova. I.A. Kechkin, Development of technological schemes for the prosesses of preparation and milling of two-component grain mixtures, IOP Conference Series. Earth and Environmental Science. 2021. 640 (3). article 6402049 (2021)

9. O.E. Bakumenko. L.N. Shanyuk, Technological aspects of the use of flax flour in food concentrates of functional purpose, Bread products. 6. P. 56-59 (2017).

10. Nechaev A.P., Traubenberg S.E., Kochetkova A. A., Kolpakova V.V., Vitol I.S., Kobeleva I.B. Food chemistry. Laboratory workshop, St. Petersburg: GIORD, 304 p, Russian (2006).

11. Norms of physiological needs for energy and food substances for various populations of the Russian Federation. MR 2.3.1.2432-08, Moscow: FC Center of Hygiene and Epidemiology of Rospotrebnadzor, 36 p. Russian (2009). 